\title{
The Eastern Baltic LNG terminal as a prospect to improve security of regional gas supply
}

\author{
Kati Kõrbe Kaare, Ott Koppel, Ando Leppiman \\ Department of Logistics and Transport \\ Tallinn University of Technology \\ 19086 Tallinn, Estonia \\ E-mail: \{kati.korbe, ott.koppel, ando.leppiman\}@ttu.ee
}

Received: March 4, 2021. Revised: March 22, 2021. Accepted: March 26, 2021. Published: March 29, 2021.

\begin{abstract}
One of the crucial issues in Europe at the moment is securing reliable gas supply. Achieving security of gas supply implies diversifying gas sources, while having enough supply, transportation, and storage capacity to meet demand peaks and supply interruptions. In 2013, the Baltic States still remain disintegrated from the rest of Europe in one crucial way: their natural gas infrastructure isolates them into "energy islands". The Eastern Baltic Sea European Union (EU) member states of Finland, Estonia, Latvia and Lithuania are the only ones which remain isolated from the present integrated EU natural gas transmission system. The gas demand in these isolated member states is approximately ten billion cubic meters $\left(\mathrm{bm}^{3}\right)$ of natural gas per year. The third energy package of EU proposes a new series of measures to promote competition and create a single European energy market. Estonia, Latvia, Lithuania and Finland now for the first time have a chance to secure their energy independence by connecting their natural gas systems with those of their European allies and evolving them into market-based trading systems. Liquefied natural gas (LNG) is an important energy source that contributes to energy security and diversity, therefore a concept of a regional LNG terminal has been proposed. In this paper the authors give an overview of the current situation and present possible future scenarios with the development of Eastern Baltic regional LNG terminal. 2013 is a crucial time as in September the decision will be made regarding weather the regional LNG terminal will be chosen as a project of common interest in the trans-European energy networks.
\end{abstract}

Keywords—LNG; security of supply; regional terminals

\section{INTRODUCTION}

More than two decades after the end of the Soviet occupation and eight years after the Baltic States joined NATO and the EU, they remain disintegrated from the rest of Europe in one crucial way: their natural gas infrastructure isolates them into "energy islands". As a Soviet-era legacy, the natural gas networks of Estonia, Latvia, Lithuania and Finland are supplied only by Gazprom through links to the grids of Belarus, Russia's Kaliningrad Oblast, and mainland Russia.

The isolation of those states from the EU's natural gas networks is incompatible both with these states' individual economic needs and with the EU's collective vision of a unified European energy market. In 2013 Estonia, Latvia, Lithuania and Finland in are closer than ever to make concrete steps securing their energy independence by connecting their natural gas systems with those of their European allies. This is the ultimate goal of the third energy package of EU, to promote competition and create single European energy market. In parallel with infrastructure planning Lithuania, Latvia, Estonia and Finland are evolving market liberalization with intention to introduce market-based trading systems.

EU energy policy now aims to couple Baltic natural gas networks with those of their EU allies in pursuit of two key strategic goals: creation of a single unified energy market in Europe; and completion of a post-Cold War Europe that is whole and free [1]. Cooperation in the framework of Baltic Energy Market Interconnection Plan (BEMIP) between eight Baltic Sea EU Member States is being carried out and a Memorandum of Understanding with an Action Plan was signed on 17 June 2009 and is going to be fulfilled.

In order to link the isolated East-Baltic region to the European natural gas market, thus enhancing security of supply, ending single supplier dependency and increasing diversification, BEMIP identified key gas infrastructure investments, including a regional LNG terminal for Estonian, Latvian, Lithuanian and Finland's needs [2].

The European Commission (EC) has considered two options for connecting the Baltic States to the European natural gas network either by interconnector and/or by an LNG import terminal. Numerous LNG projects have been proposed in recent years for the Eastern Baltic region [2]. In September 2013 according to the Action Plan concrete measures in infrastructure development are going to be agreed upon and selection into the list of Projects on Common Interest (PCI) in accordance with Trans-European Energy Networks (TEN-E) delegated acts are going to be made.

This paper focuses on comparing of the final three projects proposed to develop the Eastern Baltic regional LNG terminal and their role in improving the security of gas supply of the mentioned region.

\section{BACKGROUND}

European experts have predicted European gas demand to stay largely flat over the next twenty years due to heavy emphasis on renewable energy. Europe is expected to become an increasingly significant importer of gas as at the same time gas production in Europe itself is to fall because depletion of the United Kingdom and Dutch reserves. Through rising imports the gas prices are expected to act same way and 
according to experts Asian price levels will be reached from 2025 onwards [3].

One of the crucial issues in Europe at the moment is reliable gas supply. This subject became even more important after gas supply interruptions and limitations took place in January of 2009 in some EU countries. At present security of supply is on top of the agenda of the EC [4].

The Eastern Baltic gas market (Finland, Estonia, Latvia and Lithuania) currently has an aggregated demand of about 10 $\mathrm{bcm}^{3}$ per year (Table I), which is expected to remain flat (compound annual growth rate $0.3 \%$ ) unless major discontinuities will take place. If gas supply diversification was enhanced and the required infrastructures were developed accordingly, market could grow up to $16 \mathrm{bm}^{3}$, with the additional upside of $1.5 \mathrm{bm}^{3}$ for LNG bunkering [3].

TABLE I. NATURAL GAS ANNUAL CONSUMPTION (MiLLION M ${ }^{3}$ ) [5], [6]

\begin{tabular}{|l|c|c|c|c|c|}
\hline \multicolumn{1}{|c|}{ Country } & $\mathbf{2 0 0 7}$ & $\mathbf{2 0 0 8}$ & $\mathbf{2 0 0 9}$ & $\mathbf{2 0 1 0}$ & $\mathbf{2 0 1 1}$ \\
\hline Estonia & 1,003 & 962 & 653 & 701 & 632 \\
\hline Latvia & 1,645 & 1,665 & 1,528 & 1,821 & 1,604 \\
\hline Lithuania & 3,720 & 3,245 & 2,727 & 3,115 & 3,398 \\
\hline Finland & 4,587 & 4,728 & 4,446 & 4,701 & 4,105 \\
\hline Total & 10,955 & 10,183 & 9,585 & 10,338 & 9,739 \\
\hline
\end{tabular}

Currently, as the Great Baltic area relies entirely on Russian gas supplies and only Latvia and Finland are compliant with N1 rule, which refers to the security of supply. Several projects have been proposed to end isolation of the Eastern Baltic market, and some of them are included in BEMIP.

These projects can be clustered in three groups [3]:

- upgrades of the existing interconnections "Intra-Baltic connections";

- new pipeline connections as Balticconnector and Gas Interconnection Poland-Lithuania (GIPL);

- new LNG terminal (six projects proposed in different port locations).

A joint implementation of Intra-Baltic connections, Balticconnector and GIPL would help the area to achieve some degree of supply diversification (about 33\% of "diversified" gas, mainly in Latvia and Lithuania), but the security of supply in Lithuania would only marginally improve [3].

To expand supply options and achieve security of supply, a LNG terminal of $4 \mathrm{bm}^{3}$ per year can be considered - with potential for future scalability. According to expert's simulation, in a base case demand this terminal will be probably utilized at $50 \%$ of its capacity and Russian contracts might be utilized at minimum quantity intake. The remaining LNG capacity could provide flexibility for peak shaving. This could help to diversify further the Baltic supply mix (ca $60 \%$ of Russian gas, $20 \%$ LNG, 20\% gas imported from European network). A larger terminal would be almost unutilized in the base case demand [3].
With the assumption that each Baltic country would have to achieve the same diversification target and equally comply with $\mathrm{N}-1$ rule (see below), the location that minimizes further network upgrades and optimizes gas grid flows is Estonia [3].

Numerous LNG projects have been proposed in recent years for the Eastern Baltic region. Different port locations might be eligible for the realization of the LNG terminal ( Muuga, Paldiski and Sillamäe in Estonia, Riga and Ventspils in Latvia, Klaipeda in Lithuania) [3]

Klaipeda LNG terminal is the only project in the early stages of implementation, potentially allowing for a detailed assessment of the project cost. The adopted technical solution for Klaipeda terminal is a Floating Storage Regasification Units (FSRU) facility leased for ten years; the lease fee of 43 million euros per year covers for rent, financing cost and overheads. The total cash-out over the lease period would be 430 million euros. Project promoter Klaipedos Nafta reports the overall investment (discounted lease fees and buy-back option) to be 250 million euros [3].

The combined market of Estonia, Latvia and Finland amounts to approximately $6 \mathrm{bm}^{3}$ per year until 2020. The market opening in Estonia combined with the expiry of the Gazprom contracts implies an increasing need and opportunity for shippers to diversify their sourcing portfolio. It will further enable easier access to new entrants as new supply options become available [2].

Russian imports will, however, still play an important role in Estonian gas supply and the gas supplies from LNG terminal will supplement the existing import source [2].

\section{SECURITY OF SUPPLY}

The security of energy supply (SOS) is one of the main objectives of EU energy policy [7]. Energy security is defined as the availability of regular supply of energy at an affordable price there are availability, accessibility, affordability and social acceptability. Energy security comes at a cost and it is not a question of achieving it at any cost [8]. From a European perspective, energy security is most often discussed in terms of SOS, in other words with reference to the avoidance of sudden changes in the physical availability of energy relative to demand [9].

The definition has physical, economic, social and environmental dimensions. A physical disruption can occur when an energy source is exhausted or production is stopped, temporarily or permanently. Economic disruptions are caused by erratic fluctuations in the price of energy products on the world markets, which can be caused by a threat of a physical disruption of supplies. Recent energy market trends show that there is another cause for concern, linked to speculative price movements in anticipation of a potential disruption of supplies.

If commercial energy services and electricity are available, income is the main factor that appears to influence a household's choice of fuel. The measures of SOS can be grouped into two categories: dependence, and vulnerability, represented both in physical and economic terms. Physical measures describe the relative level of imports or the prospects 
for shortages and disruptions. Economic measures describe the cost of imports or the prospects for price shocks [10].

It is therefore a question of guarding against such changes. Energy security involves developing strategies to reduce, or protect against, risks stemming from insufficient production capacity, imported energy and also, in the case of network industries, from transmission infrastructures (and thus transit problems). The main concern here is the risk of interruption of supplies and, more particularly, whether the energy is available in sufficient quantities to meet demand [8].

The recent developments in the energy markets have heightened concerns about the feasibility of supply security, usually defined as a continuous availability of energy at affordable prices. EU countries buy more than half of their energy from non-EU sources. Since the demand for energy is growing the EU, dependence from foreign suppliers will increase over time [7].

Energy security has risen in importance on the international policy agenda during recent decades due to growing dependence of industrialized economies on imported energy consumption and the increased frequency of disruptions in supply. In this context, the current European domestic energy system is not sufficiently reliable or affordable to support sustained economic growth.

Organization for Economic Co-operation and Development (OECD) European countries are consuming more and more energy and importing more and more energy products. As a result, external energy dependence for all sectors of the economy is constantly increasing, especially for oil and natural gas. For the future, it is vitally important to be able to implement measures that will allow an orderly and effective response to the threat from energy insecurity [10].

\section{ESTONIAN SECURITY OF SUPPLY}

One possibility to describe SOS of natural gas in Baltic States is through EU regulation concerning measures to safeguard security of gas supply [11].

According to the regulation the N-1 criterion means assessment of the situation in the event of disruption of the single largest gas infrastructure delivery connection (1). If in the event of interruption it is possible to rearrange deliveries without any supply disruption, the $\mathrm{N}-1$ criterion is met.

$$
N-1[\%]=\frac{E P_{m}+P_{m}+S_{m}+L N G_{m}-I_{m}}{D_{\max }} \times 100, \quad N-1 \geq 100 \%
$$

where:

$E P_{m}-$ technical capacity of entry points (in million cubic meters per day), other than production, LNG and storage facilities covered by $P_{m}, S_{m}$ and $L N G_{m}$, means the sum of the technical capacity of all border entry points capable of supplying gas to the calculated area;

$P_{m}-$ maximal technical production capability (in million cubic meters per day) means the sum of the maximal technical daily production capability of all gas production facilities which can be delivered to the entry points in the calculated area;

$S_{m}-$ maximal technical storage deliverability (in million cubic meters per day) means the sum of the maximal technical daily withdrawal capacity of all storage facilities which can be delivered to the entry points of the calculated area, taking into account their respective physical characteristics;

$L N G_{m}$ - maximal technical LNG facility capacity (in million cubic meters per day) means the sum of the maximal technical daily send-out capacities at all LNG facilities in the calculated area, taking into account critical elements like offloading, ancillary services, temporary storage and regasification of LNG as well as technical send-out capacity to the system;

$I_{m}$ - means the technical capacity of the single largest gas infrastructure (in million cubic meters per day) with the highest capacity to supply the calculated area. When several gas infrastructures are connected to a common upstream or downstream gas infrastructure and cannot be separately operated, they shall be considered as one single gas infrastructure;

$D_{\max }-$ means the total daily gas demand (in million cubic meters per day) of the calculated area during a day of exceptionally high gas demand occurring with a statistical probability of once in twenty years.

Based on the calculations in the Joint risk assessment of security of gas supply of Estonia, Latvia and Lithuania 2012 [12] the infrastructure standard N-1 for Estonia was $59.7 \%$, for Latvia $-153.9 \%$ and for Lithuania $-27.4 \%$. Considering all three countries as a whole in the event of a disruption of the single largest gas supply infrastructure, natural gas supply line Minsk-Vilnius, the infrastructure standard N-1 was $129.7 \%$.

On 7 November 2012 Estonian transmission system operator EG Võrguteenus presented, that in accordance with the latest calculations N-1 criteria for Estonia is fulfilled (2) due to the increased pressure after the reconstruction works in Russia in the pipeline St. Petersburg-Narva [13].

$$
N-1[\%]=\frac{14+0+0+0-7}{6,7} \times 100=104 \%
$$

Although infrastructure standard N-1 calculations show that in the event of the largest capacity disruption the capacity of the remaining infrastructure should be able to satisfy total gas demand, response scenarios demonstrate that there will be gas shortage in the region due to internal bottlenecks. The main bottlenecks in the system are the capacity of meter stations on the borders as well as the Inčukalns underground gas storage facility (UGS) send-out capacity in the spring.

To maintain this risk and to improve the security of supply of natural gas to Estonia the critical infrastructure given in BEMIP Action Plan is needed. But most of it will be effective after 2020. Therefore the only option to have a real security of gas supply before 2020 is to build up in earliest conveyance the LNG supply option together with the storage of gas for vulnerable customers.in accordance with the EU Regulation concerning measures to safeguard security of gas supply. 
According to regulation EU Member States or TSOs are required to guarantee 30 days gas supply to vulnerable customers. Such customers make up approximately $5 \%$ of the Estonian market and in accordance of the regulation demand by protected customers should be taken during 30 days at one million $\mathrm{m}^{3}$ per day.

But in the case of other alternative supply facility as LNG terminal, it would lower significantly the amount of gas needed to be stored. The existence of an LNG terminal opens a possibility to supply the region with gas in very short timeframe. Several possibilities have been analyzed for quick supply but in current situation the best options are Swinoujscie and Nynashamn. Therefore the LNG terminal capacity should be sufficient to hold only five days reserve.

\section{LIQUID NATURAL GAS}

LNG is the liquid state of natural gas (NG), useful for transport/storage since LNG occupies about $1 / 600$ the volume of $\mathrm{NG}$, when the latter is in the gaseous state under normal conditions. LNG is an important energy source that contributes to energy security and diversity [14].

Since the first LNG ship arrived in Europe in 1964, the LNG industry has been steadily growing, driven by rising natural gas demand in countries where domestic production inadequately covers local needs. Initially, Asia and Africa produced the majority of LNG, but now the Middle East and Trinidad have contributed to the production of LNG and more recently USA has started to import LNG via Sabine Pass and more terminals are waiting to get export approval [15].

In 2006, Qatar became the largest LNG producer in the world [16]. The largest consuming regions for LNG include Asia and Europe and they are expected to support substantial new LNG demand growth. There is a unique advantage on liquefaction as there is a volume reduction of about 630 times on liquefaction [17], and LNG handling is more like handling oil.

The ability to convert natural gas to $\mathrm{LNG}$, which can be shipped on specially built ocean-going ships, provides consumers with access to vast natural gas resources worldwide. LNG is ideally transported in cryogenic tankers by road, ships and rail wagons. Further, tremendous cost reductions [18] have been accomplished in all parts of the LNG chain in recent years. The fall in tanker prices over the last decade led to a much wider economic reach of LNG transportation. The dramatic cost reductions for LNG liquefaction trains made LNG projects viable even if only part of the capacity is secured by long-term sales, so that the remainder could be sold on a flexible or spot basis.

As most of the undeveloped gas reserves are located far away from OECD markets, it is clear that LNG will play a key role to bring this gas to the market, when distance or natural obstacles make pipeline transport impossible. Hence the increasing supplies of LNG, accompanied by the increased flexibility in LNG trade are adding to the security of gas supply. Like all natural gases, LNG is cleaner than coal or oil and it offers an opportunity to diversify energy supplies.
Future use of LNG is expected to grow. By 2030, the LNG market would have a big change, with a five-fold increase in volume to nearly 75 billion cubic feet per day, that represents about $15 \%$ of the total gas market, up from about $5 \%$ in 2000 [19]. There are two paradigm shifts in the world gas markets that have resulted in the fact that the European gas prices are now about five times USA levels and in Asia eight times USA level.

Shale gas boom in USA from 2010 have diminished large net imports of gas to USA for only a marginal one. Due to that significant amount of demand exited the market and furthermore, USA LNG re-gasification terminals are starting to be converted into liquefaction plants and export terminals. The first operational LNG export facility, Sabine Pass terminal, is expected to be ready for exports in 2015 .

After the Fukushima catastrophe, Japan has phased out from nuclear energy, which has increased heavily the use of natural gas for power production. Having no natural gas of their own and no pipelines, this has had a significant impact on global LNG markets and has resulted in LNG cargoes for Europe to be diverted to Asia. Additionally, gas demand in Europe has significantly fallen due to the drop of coal prices and almost collapsed Emission Trading System of EU. Coal consumption in Europe has risen significantly in the last two years.

As recent advances in technology have facilitated LNG as the quickest way for many countries to diversify their supplies of natural gas, so should do Baltic States and Finland. Price wise, in the short-term then, while over supply is an issue in Germany, supplying Eastern Baltic LNG terminal could be attractive if prices are quoted on the European hub prices. A commercially viable LNG terminal serving all three Baltic countries and Finland would ensure a year-round diversified supply of gas, which is the most fundamental element required for emergence of a liquid trading hub.

Such diversification of supply would also partially undercut Gazprom's monopolist tactics, even if GIPL fails to materialize and if Inčukalns remains under Gazprom's control [1].

\section{REGIONAL TERMINALS PROJECTS IN EASTERN BALTIC}

There are several factors affecting the scope and services of the terminal, including supply possibilities, development in demand, and functionality of the terminal in terms of the type of services provided. These factors are closely interrelated and together determine the boundary conditions for the technical parameters of the terminal. [2]:

The concept of the terminal is to cover the following areas

- SOS - in form of long term capacity reservations for the Estonian and Finnish Transmission System Operators (TSO-s);

- commercial capacity for the interested gas shippers operating in Estonia, Latvia, Lithuania, and Finland; 
- $\quad$ servicing of the off-grid market in Estonia - hereunder district heating plants not connected to the network supplied via trucks;

- re-fuelling LNG driven ships via re-loading facilities for bunker barges, which could then bring their cargo to the old port in Tallinn or other locations in Estonia or along the Finnish and Swedish coast.

It is the over-all plan to be able to service the shipping industry already from 2015 when the Sulphur Emission Control Areas (SECA) enters into force. This will be done by implementing a small storage capacity only to accommodate the bunkering demand from the maritime sector. In the following the key technical parameters comprising of send out rates and tank size which are needed to accommodate the increasing demand from the sectors are discussed [2].

The overall investment for the LNG terminal and the proposed pipeline projects (Balticconnector, Intra-Baltic connections and GIPL) would be around 1.3 billion euros, covering the whole Eastern Baltic area for an addressable demand of $11 \mathrm{bcm}^{3}$ per year with an estimated increase of the regional transportation tariff of about 0.5 US cents per million British Thermal Units (MMbtu).

This will help the area to reach a diversification target of $63 \%$, by accessing to the LNG market and western European gas hubs. Additional benefits are [3]:

- increased attractiveness of Inčukalns storage, granting access to Poland and Finland;

- incremented role of Baltic countries as a transit market for Russian gas to Europe;

- balanced grid.

Two possible implementation strategies have been identified that might grant incremental benefits for the area. Those two options have been developed with the objective of equally grant to all involved countries security of supply and supply diversification [3].

The first option considers the implementation of GIPL and Intra-Baltic connections: the overall investment spending would be in the range of $690-815$ million euros the investment will address an overall demand pool of $5.5 \mathrm{bm}^{3}$ per year (Lithuania, Latvia and Estonia), with an estimated impact on the regional transportation tariff of about 0.65 US cents per MMbtu. This will help the area to reach a diversification target of $63 \%$ by accessing western European gas hubs. Additional benefits are [3]:

- increase attractiveness of Inčukalns storage, granting access to Poland and Finland;

- incremental role of Baltic countries as a transit market for Russian gas to Europe.

The second option considers the implementation of LNG, Intra-Baltic connections and Balticconnector: the overall investment spending would be in about 860 million euros, covering the whole Eastern Baltic area for an addressable demand of $11 \mathrm{bm}^{3}$ per year, with an estimated impact on the regional transportation tariff of about 0.3 US cents per MMbtu. This will help the area to reach a diversification target of $33 \%$ accessing to LNG markets. Additional benefits are [3]:

- increased attractiveness of Inčukalns storage, granting access to Finland;

- balanced grid.

In conclusion, an integrated approach to infrastructure development may balance the value from pipelines and from LNG [3]:

- proposed BEMIP pipeline investments alone do not fully allow all Baltic countries to meet $\mathrm{N}-1$ rule. Conversely, a LNG terminal in Estonia with additional investments on interconnections would meet the target;

- the diversification opportunity offered by the LNG terminal would cap the Russian gas price, although it should be considered that, at current international LNG prices, this sourcing option might not be competitive compared to historical Russian price levels;

- a $4 \mathrm{bm}^{3}$ terminal would be the optimal size to meet the limited demand of the Eastern Baltic area, and to support gas market growth through scalable investments. This dimension would also allow using storage capacity to further manage high peak demand;

- countries involved have to take full responsibility that the initiators, owners and future operators of all the projects must be independent of the existing dominant supplier in all aspects so that is serves as real source diversification.

A joint assessment of the required investments shows that Estonia (in particular Paldiski port in case of Balticconnector landing there) is the location that helps minimizing additional investments to connect the terminal to the main transmission system and to equalize benefits of supply diversification and supply security [3].

In addition to the project recommendation, as requested by EC-s Directorate-General for Energy during the BEMIP High Level Group meeting held in Brussels in September 2012, experts conducted a high level strategic assessment of Finland (Finnish regasification terminal the FinGulf project, as proposed for PCI candidate) as possible location for the Eastern Baltic regional LNG Terminal, initially out of the project's scope [3].

The FinGulf LNG Terminal would fit within the strategic goal set by the European Commission to improve both SOS and diversification in the Baltic region. It would bring the same benefit to the region than a LNG terminal located in Estonia. Furthermore, a LNG terminal in Finland has the advantage to be closer to the centre of biggest gas consumption in the region, namely Finland. However this consumption is fully covered with supplies from Gazprom and therefore it is unrealistic to expect the real need for LNG in Finland before the maturity of existing take-or-pay contract on 2025. Hence, the Balticconnector would become a «sister project» that would grant the SOS to Estonia and would enable the supply diversification to the Baltic region [3]. 


\section{ANALYSIS OF PROJECTS}

\section{A. Finland}

In Finland, Gasum Oy is the sole importer of gas; however a secondary gas market has been established on a day-ahead trading basis. Since Fortum is $50.8 \%$ owned by the State of Finland, it can be stated that the Finnish State still has a simple majority among the Gasum shareholders. This situation is unique in the region. The Finnish TSO is not unbundled, neither is there a clear plan in Finland to do so before the exemption on the Third Energy Package runs out.

There have been talks of government discussions to unbundle, but that cannot be verified from any official source. Finnish gas demand is one with the least seasonal influences in the region, mainly due to the large proportion of industrial gas clients in the market. Many off-grid import terminals are already planned in Finland, and now also regional LNG terminal project in Inkoo is promoted. It is in the early stage of development as project is in the middle of planning and environmental impact assessment procedures.

The Inkoo project location, as currently proposed, has daily capacity of 19.2 million $\mathrm{m}^{3}$ per day; hence 7.2 million $\mathrm{m}^{3}$ per day could be dedicated to serve Estonia, Latvia and Lithuania. Inkoo port is kept open by the icebreakers of the Finnish Maritime Administration in wintertime. The ice conditions are easy at Inkoo during normal winters, and thus the channel is ice free almost always. In conclusion, a regasification terminal in Finland would grant Baltic area same benefits of the Estonian one [3].

\section{B. Lithuania}

Lithuania has made the most progress. In 2011, when Lithuania adopted the EU-s Third Energy Package, it immediately announced plans for a floating LNG terminal at Klaipeda. To move quickly, Lithuania contracted for a floating LNG regasification unit, which was assessed by Balti Gaas Pöyry report in 2012 as the most advanced of any LNG project in Baltic States [20].

\section{Latvia}

Latvia is seeking EU support for its own LNG terminal in Riga. Latvia's main argument has been that its terminal would reduce construction costs compared with a terminal in Lithuania or Estonia, since Riga's proximity to the Inčukalns storage facility obviates the need to build gas storage for the terminal. However, Latvia's Baltic neighbors worry that Gazprom's control of Inčukalns would negate the strategic value of an LNG terminal in Riga. Estonia's leaders have expressed worry that as long as the Inčukalns gas storage facility remains under Gazprom's control, a regional LNG terminal in Latvia would not enhance Estonia's security of gas supply [1].

\section{Estonia}

The Estonian government has therefore argued that public control of strategic projects like the proposed LNG terminal is crucial to strengthening Estonia's energy security. Accordingly, in May 2012, state-owned companies Elering and the
Port of Tallinn announced a joint feasibility study for an LNG terminal at Muuga harbor in Tallinn. Elering, the governmentowned electricity transmission company that co-owns the Estlink-1 cable between Estonia and Finland, and which is currently constructing a second connection, Estlink-2, plans to connect its proposed LNG terminal at Muuga with a sub-sea pipeline to Finland known as Balticconnector. In addition to Elering's project at Muuga port, two separate consortia are also pursuing LNG terminals linked to Balticconnector: Sillgas in Sillamäe and Alexela at Paldiski [3].

The Balticconnector's link to Finland is crucial to the commercial viability of any Estonian LNG terminal. Estonia, with its modest natural gas demand of $0.7 \mathrm{bm}^{3}$, is too small of a market to ensure commercial viability of an LNG terminal no matter where in the country it is located. This remains true even if an Estonian terminal is connected to the markets of Latvia and Lithuania, where demand totals only $4.8 \mathrm{bm}^{3}$. By contrast, with Finland's demand of five $\mathrm{bm}^{3}$, the combined market of the Baltic states and Finland is $10.5 \mathrm{bm}^{3}$, some fifteen times larger than the domestic market. The EC, in a report it commissioned to international consulting company Booz \& Co to determine which Baltic state should receive EU financial support for an LNG terminal, concluded that a market of this size can support a regional LNG facility [3].

Regarding the specific location of an LNG project in Estonia, the EU-s Booz \& Co report concluded, "The Sillamäe project is the weakest of the three, due to being in a very early stage of development, while the other two already have clear and well-defined projects." The choice is therefore effectively between the latter two options. Differences between the Muuga and Paldiski projects are explained by supporters as follows [3]:

- Muuga's urban location poses a lower environmental threat but a higher safety threat compared with the more remote Paldiski port;

- Muuga is closer to Estonia's existing domestic gas distribution network than the Paldiski site, reducing the cost of the pipeline connection to Estonia's national grid; but

- Paldiski is closer to the Finnish port of Inkoo, reducing the length of the future Balticconnector pipeline.

The Muuga project has the additional advantage of being co-developed with Royal Vopak, a company that can integrate the Estonian terminal into its commercially attractive Baltic LNG delivery network operating from Rotterdam [3].

Ramboll has, together with the Elering/Vopak/Port of Tallinn Working Group, considered various scenarios with regard to facility scope and phasing of terminal development, including scenarios involving coverage of varying supply security service area needs (i.e. national vs. regional solutions) and consideration of phasing of commercial capacity scope [2].

Becoming a fully regional terminal means connecting to Finland via the Balticconnector. The concept behind the Balticconnector was originally to connect Finland with the gas storage in Latvia, and to allow export of gas to Estonia from Finland. The interconnector was put on hold after the 
introduction of LNG as a possibility for supply, as the routing and sizing of the interconnector would be very dependent on the location and capacity of the LNG terminal [2].

It is clear that the Balticconnector will not move forward until a decision has been taken with regard to the location of the LNG terminal [2].

\section{CONCLUSIONS}

The perpetuation of "energy islands" like currently exists amongst the Eastern Baltic countries, poses a threat not just to the energy security of the Baltic countries, but to their national security as well. The risks of gas price hikes or cutoffs also provide Moscow significant geo-economic and geopolitical leverage, which it has not shied from using against the Baltic republics and other EU members.

The Eastern Baltic gas market (Finland, Estonia, Latvia and Lithuania) currently has an aggregated demand of about ten $\mathrm{bm}^{3}$ per year which is expected to remain flat. If gas supply diversification was enhanced and the required infrastructure was developed accordingly, market could grow up to $16 \mathrm{bm}^{3}$, with the additional upside of $1.5 \mathrm{bm}^{3}$ for LNG bunkering.

Even currently Latvia and Finland, as well as in accordance with the latest information, also Estonia, are compliant with N1 criterion, which refers to the SOS, it only covers the infrastructure part and doesn't improve the supply interruptions caused by non-infrastructure means.

Therefore several infrastructure projects have been proposed to end isolation of the Eastern Baltic market from the rest of EU and improve security of supply. These projects are described as a package in the framework of BEMIP: IntraBaltic connections upgrading, new pipeline connections as Balticconnector and GIPL, regional LNG terminal in the shores of Finnish Gulf.

At the moment Inkoo in Finland, Muuga and Paldiski in Estonia are the tree competing locations for the regional terminal. A joint assessment of the required investments shows that Estonia (in particular Paldiski port in case of Balticconnector landing there) is the location that helps minimizing additional investments to connect the terminal to the main transmission system and to equalize benefits of supply diversification and supply security.

\section{REFERENCES}

[1] M.J. Bryza, and E.C. Touhy, Connecting the Baltic states to Europe's gas market. Tallinn: International Centre for Defence Studies, 2013.

[2] Pre-feasibility study for an LNG terminal in Tallinn. Tallinn: Ramboll, 2012.
[3] Analysis of costs and benefits of regional liquefied natural gas solution in the East-Baltic area, including proposal for location and technical options under the Baltic Energy Market Interconnection Plan. Milano: Booz \& Company, 2012.

[4] A. Davis, A. Jesinska, A. Kreslins, V. Zebergs, and N. Zeltins, "Evaluation of a risk level of gas supply of the Baltic countries and risk criteria of UGS," in Proc. 24th World Gas Conf., Buenos Aires, 2009.

[5] A. Mäe, "Liquefied Natural Gas (LNG) Terminal for Eastern Baltic," Geopolitika, June 5th, 2012 [E-journal] Available: http://www.geopolitika.lt/?artc=6077.

[6] M. Roodi, and Ü. Ehrlich, "Renewable Electricity in Estonia Discrepancy between State Subsidies and Private Demand," Recent Advances in Energy and Environmental Management, 13, pp. 66-71, 2013,

[7] C. Le Coq, and E. Paltseva, "Measuring the security of external energy supply in the European Union," Energy Policy, 37, pp. 4474-4481, 2009.

[8] C. Clastres, and C. Locatelli, "European Union energy security: the challenges of liberalisation in a risk-prone international environment," in Proc. 9th int. conf. European energy market (EEM 2012), Florence, Italie, 2012.

[9] C. Winzer, "Conceptualizing energy security," Energy Policy, 46, pp. 36-48, 2012.

[10] V. Constantini, F. Gracceva, A. Markandya, and G. Vicini, "Security of energy supply: comparing scenarios from a European perspective," Energy Policy, 35, pp. 210-226, 2007.

[11] "Regulation (EU) No 994/2010 of the European Parliament and of the Council of 20 October 2010 concerning measures to safeguard security of gas supply and repealing Council Directive 2004/67/EC," Official J. European Union, L295/1, 2010.

[12] Joint risk assessment of security of gas supply of Estonia, Latvia, Lithuania 2012. Baltic Energy Market Interconnection Plan (BEMIP) Focus Group on Regional Cooperation, 2013.

[13] R. Bogdanovitsh, "Natural gas infrastructure in Estonia and LNG," (in Estonian), 2012 [On-line] Avalaible: http://ftp.jlp.ee/public/Energeetikafoorum/.

[14] P.-M. Spanidis, "Lessons Learnt from Establishing Liquefied Natural Gas Facilities in Countries of North Mediterranean Sea," Recent researches in environmental and geological sciences, 4, p. 21, 2012.

[15] G.A. Chamberlain, "Management of large LNG hazards," in Proc. 23rd World Gas Conf., Amsterdam, 2006.

[16] A.S.R. Kuramoto, N. Magalhães Bueno, W. Da Silva Frazão Filho, E.M. Dias, and C.F. Fontana, "Automation of Port Facilities for Import of GNL," in Proc. 13th WSEAS Int. Conf. on Systems, Stevens Point, 2009.

[17] T. Shukri, and F. Wheeler, "LNG technology selection," Hydrocarbon Engineering, 2, pp. 71-76, 2004.

[18] S. Cornot-Gandolphe, "LNG cost reductions and flexibility in LNG trade add to security of gas supply," Energy Prices \& Taxes, 1, pp. xxixxxvi, 2005.

[19] H.B. Gooi, P.L. So, E.K. Chan, E. Toh, and H. Gan, "Strait ahead. Toward a sustainable, economic, and secure electricity supply in Singapore," IEEE Power \& Energy Magazine, pp. 65-74, July/August 2012.

[20] Liberalisation of the Estonian Gas Market. Tallinn: Pöyry Management Consulting (UK) Ltd, 2011.

\section{Creative Commons Attribution License 4.0 (Attribution 4.0 International, CC BY 4.0)}

This article is published under the terms of the Creative Commons Attribution License 4.0 https://creativecommons.org/licenses/by/4.0/deed.en US 